\title{
Research on the Influence of Chinese Tea Technology on the World Tea Industry
}

\author{
Wu Yan'1, Zhangzhi Ge1, Liyong Xiong² \\ ${ }^{1}$ University of Science and Technology of China, Hefei, China \\ ${ }^{2}$ The Party School of Hefei Municipal Committee of the CPC, Hefei, China \\ Email: syc16@mail.ustc.edu.cn
}

How to cite this paper: Yan, W., Ge, Z.Z. and Xiong, L.Y. (2020) Research on the Influence of Chinese Tea Technology on the World Tea Industry. American Journal of Industrial and Business Management, 10, 135-143.

https://doi.org/10.4236/ajibm.2020.101009

Received: December 23, 2019

Accepted: January 11, 2020

Published: January 14, 2020

Copyright $\odot 2020$ by author(s) and Scientific Research Publishing Inc. This work is licensed under the Creative Commons Attribution-NonCommercial International License (CC BY-NC 4.0). http://creativecommons.org/licenses/by-nc/4.0/

\begin{abstract}
This paper mainly explores the relationship between Chinese tea technology and world tea industry by discussing the influence and function of Chinese tea technology on Chinese tea industry. And it is concluded that the Chinese tea technology has given birth to the world tea industry; the world tea industry has continuously developed on the basis of Chinese technology, and has achieved the prosperity of the world tea industry.
\end{abstract}

\section{Keywords}

Chinese Tea Technology, World Tea Industry, Technological Innovation

\section{Introduction}

Tea originated in China and has a long history. Chinese tea technology also has a long history. Generally speaking, Chinese tea technology development can be divided into four periods: the origin of tea making; the transformation of tea making; the development of tea making; and the sprouting of tea making mechanization. At present, there are few researches on the influence of Chinese tea technology on the world tea industry and how it affects the world tea industry. This article discusses the origin of tea, the historical evolution of Chinese tea technology, and the Chinese tea industry and the world tea industry, in order to explore the internal relationship between Chinese tea technology and the world tea industry and the impact of Chinese tea technology on the world tea industry.

\section{The Origin of Chinese Tea}

China is the country of origin of tea trees and the first country to discover and use tea. The history of tea production in China has more than 4000 years [1] (p. 16). Legend has it that wild tea trees were found in China and detoxified with 
wild tea. At the time of King Zhou Wu's cutting, tea had become a tribute. During the Spring and Autumn Period, tea was used as a sacrifice and vegetable. During the Western Han Dynasty, tea has become a commodity. During the Western Jin Dynasty, tea trees cultivated in temples were also picked and made into tribute tea. During the Northern and Southern Dynasties, as Buddhism prevailed, many temples were built in the mountains. The southern temples basically planted tea trees. And many temples produced famous tea. From the analysis of the biological characteristics and historical use of the large tea tree, it is more accurate to say that the tea tree is native to the Dalou Mountains in the Yunnan-Guizhou Plateau [2] (p. 30).

In the Tang Dynasty, tea drinking customs spread to all parts of the country, and the scope of tea production areas was further expanded. The ruling classes advocated tea drinking. At that time, there were more than 50 tribute tea categories and an orderly tribute tea system was formed. In the Song Dynasty, tribute tea was further developed. At that time, tribute tea houses were also established in Fujian and other places to specifically manage the related matters of tribute tea production. And there were more and more tribute tea items. The tribute tea system in China continued to the Xianfeng period of the Qing Dynasty, and ended with the decline of the Qing Dynasty rule [3]. At present, our country has many tribute tea to come down. After many years of evolution, they still retain the original name and traditional quality style, become historical tea.

Today, Chinese tea can be divided into six major famous teas: black tea, white tea, yellow tea, green tea (oolong tea), green tea, black tea. Each tea has a different flavor and aroma as well as different health functions. There are thousands of different flavors of tea varieties and tea products.

\section{The History of Chinese Tea Technology}

Over $6000 \mathrm{BC}$, there were tea trees in China. It was not until the shennong period, more than $2000 \mathrm{BC}$, that the Chinese laboring people discovered that the fresh leaves of wild tea trees could be detoxified. So they began to plant them artificially. In the Eastern Jin Dynasty's "Wang Yang Guo Zhi Ba Zhi”, written by $\mathrm{Qu}$ Chang, it was recorded that when King $\mathrm{Wu}$ of Zhou allied with the local minorities in Ba shu to fight against Shang Zhou, tea trees had been planted in the gardens of the people of Ba shu and had been as tribute. Tea needs to be processed as a tribute, and the process is like sunbathing, Due to the role of light and heat, the quality has changed a lot. And it has a special flavor like the present white tea. China has a history of tea making for at least three thousand years.

\subsection{The Origin Period of Tea Making}

From more than $2000 \mathrm{BC}$ to the end of the tang dynasty in $96 \mathrm{AD}$, Chinese tea making technology developed from the fresh leaves of wild tea trees to the steamed green tea balls of the tang dynasty. From the discovery of wild tea plants to the tang dynasty as a popular beverage, tea technology in China underwent 
complex changes. At the beginning, the tea was raw boiled, and then dried collection, until the Wei dynasty the tea cakes was made and dried. When drinking, grind and brew. From the making process of cake tea, people found that grass smell of cake tea is very strong; so people began to explore how to remove the green cake tea. Later, people invented the steamed green method. That is, fresh leaves steamed, mashing cake perforation, through the drying. Since then, the quality of tea has improved considerably. In the process of making cake tea, people found that the tea juice has a bitter taste. After that, it was found that a way can reduce the bitter taste of the tea. That is, fresh leaves were first washed and then steamed, then pressed to remove the leaf juice, and finally made into cakes. India now making green tea by squeezing out part of the leaf juice, is to learn our method of tang dynasty.

The working people of China made the superior tea, which was approved by the feudal emperor at that time. So they asked people to make the superior tea in large quantities to pay tribute to the royal family. Although the tribute tea system was a very cruel system of exploitation by the feudal class, it greatly promoted the technological reform of tea production. The production of tribute tea includes steaming tea, pressing tea, grinding tea, making tea, over-yellow, drying tea and other processes. Gongcha is delicately made. After tea buds are picked, they are first soaked in water and then steamed. After steaming, they are rinsed with cold water to quickly cool the tea leaves, in order to keep them green. After the cold with a small press to water, and then with a large press to the juice, the number of times is variable according to the actual situation. After the juice is removed, put it into a pot and mix with water to grind it. The cakes are dried. The drying times depend on the thickness of the tea cakes, which usually range from 10 - 15 times. These technical measures are good or bad. On the plus side, rinsing with cold water quickly and keeping it green is the method currently used to make steamed green tea; cold water is changed to air blowing, which is an improvement on this basis. On the negative side, squeezing water and juice reduces the original taste of the tea and reduces the quality of the tea, so the steamed green tea process is therefore eliminated.

\subsection{A Time of Revolution in Tea Making}

From 961 to 1368, Chinese tea-making technology evolved from steamed green tea to stir-fried green tea. This period lasted from the song dynasty to the Yuan dynasty for more than three hundred years. It was changed from steamed green tea to steamed green tea, and then changed from steamed green tea to fried green tea. In the process of making steamed green tea, the bitter taste of tea cannot be completely removed, and the aroma of tea is not right. The tea retains the original flavor, because the manufacturing process changed from steaming green tea group to steaming green loose tea. The modern Japanese manufacturing process of milled tea is based on the practice of steamed green tea in China at that time. Unlike Japan's milled tea, when drinking, our country does not grind it into shreds, but brews it with whole leaves. At that time, the famous steamed green tea varie- 
ties in China were Gusong Purple Bamboo Shoots, Piling Yangxian, Shaoxing Rizhu, Wuyuan Zheyuan, Xinglong Shuangjing, etc. Drinking tea is quite common, and related appreciation methods have been developed to distinguish the quality of tea. After countless practical explorations of reciprocating cycles, by the end of the 12th century, China's tea-making technology was improved from steamed green tea to fried green tea. This can make full use of dry heat, give full play to the excellent aroma of tea, and solve the shortcomings of steamed green aroma and low flavor, which is a change in Chinese tea-making technology.

\subsection{The Development Period of Tea Making}

From AD 1368 to 1700 , although it was also more than 300 years, China's tea technology developed rapidly during this period. From stir-fried green tea to the development of a variety of tea, the color is rich. In the process of making roasted green tea, people found that the aroma of drying is not as good as frying. By stir-frying, people invented the method of stir-frying green tea. Through continuous attempts, people gradually changed the tea making technology, and the invention of new tea making technology also appeared. More and more tea colors were produced, such as pine, pearl tea, dragon well, melon slices, mao feng and other famous teas appeared one after another. Although they all belong to baked green and Fried green tea, each has its own characteristics, rich and colorful. On this basis, people have invented five major teas: yellow, black, white, green and red.

\subsection{Tea Mechanization in the Bud}

In our country, the use of water wheel power grinding to make tea has appeared in the tang and song dynasties [4]. In modern times, the technology of making tea using machinery was started in the early 20th century in foreign countries. China started it after the founding of New China. After China invented the method of tea making, the countries that had the conditions to develop tea production came to China to learn the technical knowledge of tea production and vigorously develop their tea production. Based on natural adaptation, Japan was the first country to develop green tea production, followed by India (including now Pakistan and Bangladesh), Sri Lanka, and Indonesia. Tea production in India was owned by British capitalists, so tea technology improved quickly. In the early 20th century, India first adopted machines to produce graded black tea. Subsequently, Japan used machinery to produce steamed green tea. At that time, the Chinese tea production technology is backward. And the modes of production are small-scale manual operations. After the founding of new China, China vigorously developed tea production and implemented many technological innovations. At the beginning, China set up large-scale red and green tea processing plants in tea districts all over the country, and the production of red and green tea was fully mechanized. Various tea-making machines have appeared one after another, and have been gradually promoted to the countryside. Recently, China has advanced to electrification, continuity, serialization and automation. 


\subsection{The Present Situation of Tea Making Technology in Modern China}

The development of Chinese tea is also closely related to the support of the world, especially China's science and technology. Taking the development of tea production technology as the main line, China's modern tea technology is mainly focused on the focus of tea garden construction and transformation. The selection, breeding and approval of a large number of new tea trees and the improvement of old tea gardens and the construction of new tea gardens have greatly increased the area of tea planting in China. In 1978, the area of tea planting increased by 5.2 times compared with 1950 [5].

The second stage is the stage of vigorously promoting the production technology of tea name optimization, whose technical development route is embodied in the production of green food in China proposed by the ministry of agriculture of China in 1987. In 1990, the first organic tea product was produced in China, and then the processing of famous green tea went into mechanized production. In 1999, the ministry of agriculture proposed pollution-free tea production, and China's tea processing technology changed from green to organic. After entering into the high-quality organic tea, the emphasis on pollution-free tea production has gradually realized the optimization of the name of tea and the safe production, effectively ensuring the people's basic needs for tea quality and safety. In 2000, the output of famous and excellent tea in China reached 135,000 tons (27,000 tons in 1990), and the proportion of the output of famous and excellent tea in the total tea output increased from 5\% in 1990 to $19.8 \%$ in 2000, an increase of nearly four times [6]. In 2000, the first tea tree gene (polyphenol oxidase) was cloned. In 2002, China introduced clean production of tea. In 2003, there were many developments in tea deep processing in China. In 2005, theanine was successfully synthesized from microorganisms.

After the expansion of tea garden area in the first stage and the optimization of tea production name in the second stage, the main tea technology in the third stage focuses more on the intensive and modernized construction of tea garden. It combines the technological achievements of the first two stages, and carries out tea technology research and development based on the needs of consumers and tea deep processing, such as the combination of improved tea planting and industrialization, the clean and standardized production of tea plantations, which make full use of and promoting the advantages of China's tea resource endowment. The development of tea garden construction has laid a foundation for the further development of tea technology in China. The standardized tea garden and mechanized operation can not only greatly improve the output and production efficiency, but also ensure the output level of Chinese tea. In 2007, the ministry of agriculture put forward the tea development policy of "stabilizing the area, improving yield per unit area, improving quality and improving efficiency". In 2009, the ministry of agriculture proposed standard tea construction. 


\section{The Influence of Chinese Tea Technology on the Development of World Tea Industry}

\subsection{China's Tea Technology Development Spawning the World's Tea Industry}

Due to the seclusion of Chinese feudal society, Chinese tea technology has been in the stage of "experiential tea" for a long time. The development of tea technology in the world must be the integration of traditional Chinese tea technology and modern western science and technology, or the use of modern western science and technology to improve traditional Chinese tea technology [7].

With the spread of Chinese tea in foreign countries, Chinese tea, tea trees, tea customs and tea-making technology have also spread to the world with the development of sino-foreign cultural exchanges and commercial trade. It was first introduced to Japan and Korea, and then to Indonesia, India, Sri Lanka and other countries by south sea. In the 16th century, it spread to European countries, then to the American continent, and from the north to Persia, Russia and other countries.

In the middle of the tang dynasty, Chinese tea seeds were brought to Japan for cultivation, and tea trees began to spread to the world. In 805, a Japanese monk named Zuicheng returned home from the Guoqing temple in Tiantai mountain with tea seeds planted in the river near Japan [8]. This is the earliest record of the spread of Chinese tea. Later, the Japanese monk Nanura Zhaoming learned the tea-drinking customs of Jingshan tea banquet and tea fighting in Jingshan Temple, and brought them back to Japan. On this basis Japan gradually formed their own tea ceremony. Since then, the tea industry in Japan has been formed. With the deepening of trade and cultural exchanges between China and Japan, the tea industry in Japan has been developing continuously.

India is the largest producer and exporter of chopped red tea, and its tea origins in China. Although India also has wild tea trees, Indians do not know how to grow and drink tea. Until 1780, British and Dutch talents began to introduce tea seeds from China to India to grow tea. Today, the most famous red tea is produced in Assam, which was introduced from China in 1835. Chinese experts have traveled to India to guide tea growing and brewing techniques, including the production of small varieties of black tea. It wasn't until the invention of the tea cutter that red tea became a global staple drink. The word "tea" in western languages is mostly derived from the pronunciation of "tea" in Xiamen, Fujian, a maritime trading port, and the cantonese dialect. China gave the world the name of tea, the knowledge of tea, the cultivation of tea and the technology of tea making. Therefore, the tea industry of various countries in the world, directly or indirectly, is inextricably linked with China's tea technology.

China is not only the birthplace of tea trees, but also the first country to make tea. Due to Chinese and foreign trade and cultural exchanges, Chinese tea and tea technology spread to Japan, North Korea and other places, and later to the world. Therefore, China's tea technology has given birth to the world tea industry and affected the development of the world tea industry. 


\subsection{Chinese Tea Technology Promoting Development of World Tea Economy}

The continuous advancement of Chinese tea technology has promoted the continuous development of the Chinese tea industry, which has continuously expanded the scale of the Chinese tea industry. At the same time, it has made tea a regular beverage throughout the country, and then spread to the world with Chinese and foreign trade and cultural exchanges.

At present, there are more than 60 countries and regions in the world planting and producing tea, including 22 countries in Asia, 21 countries in Africa, 11 countries in America, 3 countries in Oceania, and Russia and Portugal are the tea producers in Europe [9]. According to the statistics of the international tea committee, the cultivated area of the world was 3.31 million hectares in 2007, and reached 4.72 million hectares in 2016, with an increase of 1.41 million hectares in ten years, an increase of $42.6 \%$ over 2007 . Among them, the cultivated area of China's tea was 2.96 million hectares in 2016, accounting for $62.9 \%$ of the cultivated area of the world's tea, ranking first in the world. China accounts for most of the growth in the world's tea acreage. The world's total tea output reached 5.05 million tons in 2016, an increase of 1.649 million tons over a decade earlier. The world's top 10 tea producers in 2016 were China, India, Kenya, Sri Lanka, Turkey, Vietnam, Indonesia, Argentina, Bangladesh and Japan. China's total tea volume in 2016 was 2.433 million tons, accounting for 44.2 percent of the world's total, ranking first in the world. In 2016, the world's tea export value, China's tea export value was 1.485 billion US dollars, ranking first in the world, exceeding Kenya and Sri Lanka [10].

There are more than 50 countries growing tea on five continents, and 120 countries import tea from China. More than 6 billion people in the world like tea and tea culture. It can be said that China has given the name of the world tea, tea has added health and happiness to the people of the world, and the world tea industry has become more prosperous due to Chinese tea. Therefore, the continuous development of Chinese tea technology pushes Chinese tea to the world, promotes the development of global tea trade, and promotes the prosperity and development of world tea economy.

\subsection{The Development of Chinese Tea Technology Enriching the Exchange of World Tea Culture}

Tea culture is based on tea and reflects a clear spiritual content. It is a highly harmonious and unified product of material civilization and spiritual civilization [11]. In 805, a Japanese monk named Zicheng returned home from the Guoqing temple in Tiantai mountain with tea seeds planted in the river near Japan. This is the earliest record of the spread of Chinese tea. Tea culture was introduced to Japan in the 12th century. The Japanese zen master Rong xi brought tea back to Japan, and the tea ceremony was further innovated and developed in Japanese culture, giving rise to the Japanese tea ceremony. Japan is the second largest exporter of 
tea in China. The main reasons are the continuous development of tea culture, the continuous recognition of tea health functions by consumers, and the diversified development trend of tea consumption patterns [12] [13] [14]. As early as the Three Kingdoms of Korea, tea was introduced from China to the Korean Peninsula as a ceremony. Korean tea etiquette originated from ancient Chinese tea drinking customs, and formed by integrating Zen culture, ethics of Confucianism and Taoism, and Korean traditional etiquette.

In history, the British who never planted a piece of tea, used tea imported from China to create their own unique and world-famous "English afternoon tea". With the wide spread of Chinese tea ceremony, tea art and tea knowledge, various countries in the world have formed a variety of tea culture lifestyle, and jointly built the Great Wall of world tea culture.

The continuous progress of tea technology promotes the continuous development of China's tea industry, which makes the scale of China's tea industry continuously expand. Chinese tea has spread to all parts of the world, and is attached to the tea culture, such as serving tea by guests, relaxing with tea, exercising with tea and the tea ceremony concept of "Qing dynasty, respect, harmony and beauty". These have a profound impact on tea lovers in various countries, thus promoting the spread and communication of tea culture around the world.

\section{Conclusions}

China tea has a long history. With the rapid development of tea technology and agricultural technology at that time, the Chinese tea industry prospered and developed, and the tea spread to Japan, North Korea, India, and the world thus giving birth to the world tea industry and continuously influencing the development of the world tea industry. The world's tea industry continues to develop and innovate on the basis of China's tea technology, making tea spread throughout the world and developing into a beverage that people all over the world like. Therefore, China's tea technology gave birth to the world's tea industry and promoted the continuous development of the world's tea industry. The world tea industry continues to develop on the basis of China's tea technology innovation, forming different tea consumption habits and tea consumption markets in different countries.

Therefore, China should continue to strengthen the knowledge innovation in Chinese tea industry and improve the basic research and technical research of tea. In addition, we also should vigorously train senior talents in tea technology innovation, strengthen international tea technology exchanges, constantly improve Chinese tea technology level, and promote the high-quality development of Chinese tea industry. At the same time, we should also take the world tea industry market as the orientation, and construct the tea technology innovation management mode guided by the "target-demand-system" three-dimensional integration. So that China tea can not only meet the domestic consumption demand, but also meet the world tea consumption demand. 


\section{Funding}

"Research on Development and Management of New Tea Drink under the Health Theory" funded by Funding Project for Scientific Research Operating Expenses for Universities and Colleagues from University of Science and Technology of China in 2018 (Project No. WK2160000012).

Key research and development project of Anhui Province in 2019: "Development for Winter Tea and its Derivatives" (Project No. 201904a06020014).

\section{Conflicts of Interest}

The authors declare no conflicts of interest regarding the publication of this paper.

\section{References}

[1] Chen, Y. (2008) General History of the Tea Industry. 2nd Edition, China Agriculture Press, Beijing, 4.

[2] Zhuang, W.F. (1989) On the History of Chinese Tea. Science Press, Beijing, 18-28.

[3] Mao, G.F., Lang, J.B., et al. (2005) Development of Tea Production and Transformation of Aging Tea Garden. Inner Mongolia Agricultural Science and Technology, 10, 94-95.

[4] Wang, S.G. and Ling, G.H. (2005) Mechanization of Tea Production Promotes the Development of Famous Tea. China Tea Processing, 1, 12-13.

[5] Fan, L.L., Guo, W.J., et al. (2014) Talking about Tea Industry Planting and Development. China Agricultural Information, 21, 153-154.

[6] Yang, Z.J. (2000) Chinese Tea Industry History, Current Situation and Future. Journal of Tea Business, 1, 7-8.

[7] Zhu, Z.Z. (2008) Preliminary Exploration of Tea History. China Agriculture Press, Beijing, 113.

[8] Xu, B. (2014) Chinese and Foreign Monks Who Promoted the Development of Tea Production and the Spread of Tea Culture in China. Shanghai Tea Industry, 3, 32-33.

[9] Xu, Y.C. (2004) World Tea Flourishes throughout Global Production. Tea, 4, 30.

[10] Yang, B. (2017) Research on the Influencing Factors and Competitiveness of Chinese Tea Export Trade. Fujian Tea, 1, 44-45.

[11] Cheng, Q.K. (2008) History and Future of Chinese Tea Culture. Chinese Tea, 7, 8.

[12] Sui, G.J., Shen, M.H., et al. (2005) Research on High-Tech Industrialization Based on Regional Differences in Patent Level. Management World, 8, 87-93.

[13] Santarelli, E. and Piergiovanni, R. (1996) Analyzing Literature-Based Innovation Output Indicators: The Italian Experience. Research Policy, 5, 689-711. https://doi.org/10.1016/0048-7333(95)00849-7

[14] Gittelman, M. (2008) A Note on the Value of Patents as Indicators of Innovation: Implications for Management Research. Academy of Management Perspectives, 22, 21-27. https://doi.org/10.5465/amp.2008.34587992 